\title{
BMJ open A 12-month incidence of exercise- related injuries in previously sedentary community-dwelling older adults following an exercise intervention
}

To cite: Little RMD, Paterson DH, Humphreys DA, et al. A 12-month incidence of exercise-related injuries in previously sedentary community-dwelling older adults following an exercise intervention. BMJ Open 2013;3:e002831.

doi:10.1136/bmjopen-2013002831

- Prepublication history for this paper is available online. To view these files please visit the journal online (http://dx.doi.org/10.1136/ bmjopen-2013-002831)

Received 5 March 2013 Revised 10 May 2013 Accepted 13 May 2013

This final article is available for use under the terms of the Creative Commons Attribution Non-Commercial 2.0 Licence; see http://bmjopen.bmj.com

For numbered affiliations see end of article.

Correspondence to Robert M D Little; rlittle7@alumni.uwo.ca

\section{ABSTRACT}

Objectives: Fear of injury is reported as a barrier to exercise by older adults. However, the literature is limited in describing exercise injuries in older adults.

Design: This study prospectively evaluated the 12-month incidence of exercise-related injuries to community-dwelling older adults $(n=167$ respondents; 63 men, 104 women; mean age $69 \pm 5$ year).

Methods: A questionnaire developed for use in older adults was administered to document self-reported injuries. Linear regression analysis was conducted to identify covariates related to injury outcomes.

Results: 23 people (14\%) reported injuries. $41 \%$ of injuries were to the lower extremities, where the most common type was overuse muscle strains $(32 \%, n=7)$. Overexertion was the most common cause of injury $(n=9)$ and walking accounted for half of the activities during which injury occurred. $70 \%$ of injuries required medical treatment. $44 \%$ were not able to continue exercising after injury and return-to-activity time varied from 1 to 182 days. Sex, age and exercise volume were not significantly associated with injury occurrence.

Conclusions: These results showed similar, or lower, exercise-related injury rates as compared with previous reports on younger and middle-aged adults; however, the definition of, and criteria for, 'injury' reporting varies in the literature. This study indicates that older adults taking up exercise are not at increased risk of injury versus younger age groups.

\section{INTRODUCTION}

Fear of injury is reported as a common barrier to exercise by older adults. ${ }^{1-3}$ However, the literature describing an increased rate of exercise injuries in older adults is limited in substantiating these concerns. ${ }^{4}$ Historically, the literature has focused on the description of acute traumatic sport-related injuries based on emergency department surveillance systems, without variable breakdowns for specific age groups. ${ }^{4}$ Nevertheless, descriptions of the types and

\section{ARTICLE SUMMARY}

Article focus

- The literature does not adequately describe exercise-related injuries in older adults.

- The literature also does not currently include any description of the effectiveness of older adultfocused exercise interventions in decreasing injury incidence in the older adult population.

- The purpose was to address these gaps in the literature and describe the 12-month incidence of, and injuries to, previously sedentary community-dwelling older adults who had just completed a supervised older adult educationa exercise programme.

Key messages

- Older adults taking up exercise are not at increased risk of injury.

- Participation in an intervention, where the instruction of safe participation is taught, results in injury incidence rates similar to that of younger adults.

Strengths and limitations of this study

- The strengths include a relatively large sample focused on the older adult age-range and the use of a tool previously developed for older adults.

- The limitations include a small sample size in terms of providing a very large incidence rate for injuries and descriptions. Also, the present sample is a relatively healthy community-dwelling older adult population that may not reflect the injury rates of those in assisted-living or those with major mobility issues.

frequencies of injuries focusing on recreationally active adults have emerged. ${ }^{5-8}$ However, few studies focus on the older adult age-range participating in general physical activities (vs sport). ${ }^{9-11}$ In addition, until recently, there did not exist a survey tool that had been validated in the older population and that comprehensively obtained data on all variables 
needed to properly describe injuries. Therefore, the literature does not adequately describe exercise-related injuries in older adults, particularly those with chronic and overuse types of musculoskeletal injuries.

Despite the general lack of surveillance in this area, recommendations for older adults to avoid injury stress the importance of individualised and/or monitored physical activity programmes, ${ }^{12-14}$ with the need for physical fitness and injury prevention programmes being directed towards older adults. ${ }^{13}$ Again, the literature does not currently describe the effectiveness of such initiatives on the injury rates of physically active older adults. Therefore, the purpose of this study was to report and describe the 12-month incidence of injuries to previously sedentary community-dwelling older adults ( $>60$ year) who had just completed a supervised older adult exercise programme.

\section{METHODS}

A convenience sample of 167 individuals over the age of 60 years participated in the study. The participants had completed an older adult exercise intervention and this study represents the 12-month prospective tracking of these individuals. Briefly, participants were recruited from five diverse geographical communities in Canada (Calgary, and Edmonton, Alberta; Winnipeg, Manitoba; and Hamilton, and London, Ontario) and had been participants in an older adult exercise intervention. Participants who were sedentary preintervention, community dwelling and free of major mobility disability were included in the study. The community-based intervention, the Get Fit for Active Living (GFAL) programme is an 8-week experiential and educational exercise programme designed for older adults and led by trained fitness facilitators. For each of the 8 weeks of the programme, participants attended two exercise sessions and one education session with each session being $1 \mathrm{~h}$ in duration. Education topics included: benefits of physical activity, strengthening and stretching, healthy eating, exercise adherence, exercise for various chronic diseases, safety and maintaining an exercise programme at home or in the community. An educational GFAL manual is provided for the participants. In week 1 of the programme, the educational session focused on safety precautions including gradual progression and proper technique, equipment and attire. The two exercise classes each week included a cardiovascular warm-up, cardiovascular activity at a level of $65-80 \%$ of predicted maximum heart rate, a cardiovascular cool-down, muscular strengthening, balance and flexibility. A focus of the experiential exercise sessions is the instruction and adoption of proper technique. The programme progresses to meet Canada's Physical Activity Guidelines for Older Adults. Postprogramme, participants were encouraged to continue their exercise routines on their own and in a setting of their choosing with no contact from the researchers. All of the experimental procedures were approved by
Western University's Ethics Committee for Research on Human Subjects. Participation was voluntary and all participants gave written informed consent.

The participants were contacted at 6-months and 12-months postprogramme participation and an exercise-related injury questionnaire was administered by a single research assistant via telephone. The results are reported for the duration of the 12-month follow-up. During the telephone interview, all participants were asked, "In the last 6 months, or in the 6 months since the last follow-up in (date), have you had an injury that occurred while you were participating in exercise-type activities, where injury is defined as a self-reported muscle, tendon, bone, ligament, or joint injury?" Those who responded with a 'yes' were read a series of questions. The questionnaire, developed for use in an older adult population, and which is described elsewhere, ${ }^{4}$ was based on the International Classification of External Causes of Injuries ${ }^{15}$ and asked participants about their exercise-related injuries incurred in the specified previous time period. Other items included the mechanism of injury, cause of the injury, anatomical site of the injury, location of injury and type of treatment sought.

To assess the total physical activity levels, participants were telephone-administered the Phone-FITT, a physical activity questionnaire designed specifically for community-dwelling older adults. ${ }^{16}$ The Phone-FITT measured the frequency and duration of household and recreational (including exercise-based) physical activities. Exercise frequency was calculated as the number of times per week participants reported participation in exercise-type activities.

Data analyses were performed with the Statistical Package for the Social Sciences (SPSS) V.19.0 (Ireland, 2010). All descriptive data are presented as mean \pm SD. Frequency distributions were examined for categorical variables. Univariate and stepwise linear regression analyses were conducted to identify covariants (age, sex, total volume of physical activity and exercise frequency) related to injury outcomes.

\section{RESULTS}

Information regarding exercise-related injuries in community-dwelling individuals was obtained for all 167 participants (mean age $69 \pm 5$ year; 104 women, 63 men) completing the 12-month follow-up. Participants were 92\% Caucasian, $57 \%$ were married and $81 \%$ were retired. Thirty-nine per cent of participants reported their self-rated health as being 'very good', compared with $42 \%$ reporting their health as being 'good'. Fifty-eight per cent of participants had at least one selfreported health condition. The top three chronic conditions reported by participants were hypertension $(24 \%)$, arthritis (14\%) and thyroid condition $(8 \%)$. The mean body mass index of the sample was $28.8 \pm 5.4$ years.

Twenty-three of $167(13.8 \%)$ participants reported an exercise-related injury during the 12-month period. 


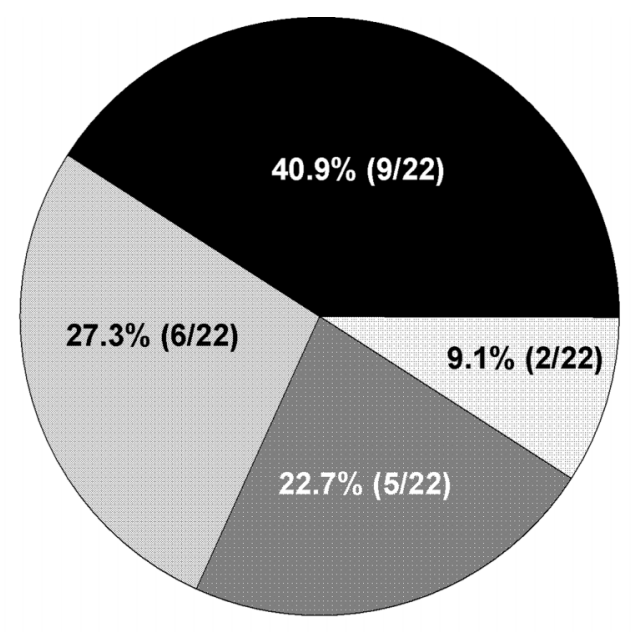

Lower Extremity (thigh, lower leg, ankle and/or foot), 40.9\% Upper Extremity (upper arm,forearm, hand and/or wrist), 27.3\%

$\square$ Trunk (chest, upper/lower back,abdomen,spine and/or pelvis), $22.7 \%$ Multiple Body Regions, 9.1\%

Head and/or Neck. 0\%

Figure 1 Body part injured.

There were eight injuries reported by male participants $(12.6 \%)$ and 15 by female participants (14.4\%). Lower extremity injuries totalled $41 \%$, whereas $27 \%$ were in the upper extremity, 23\% involved the trunk and $9 \%$ affected multiple areas (figure 1). The most common type of injury was the repetitive/overuse muscle strain (32\%,
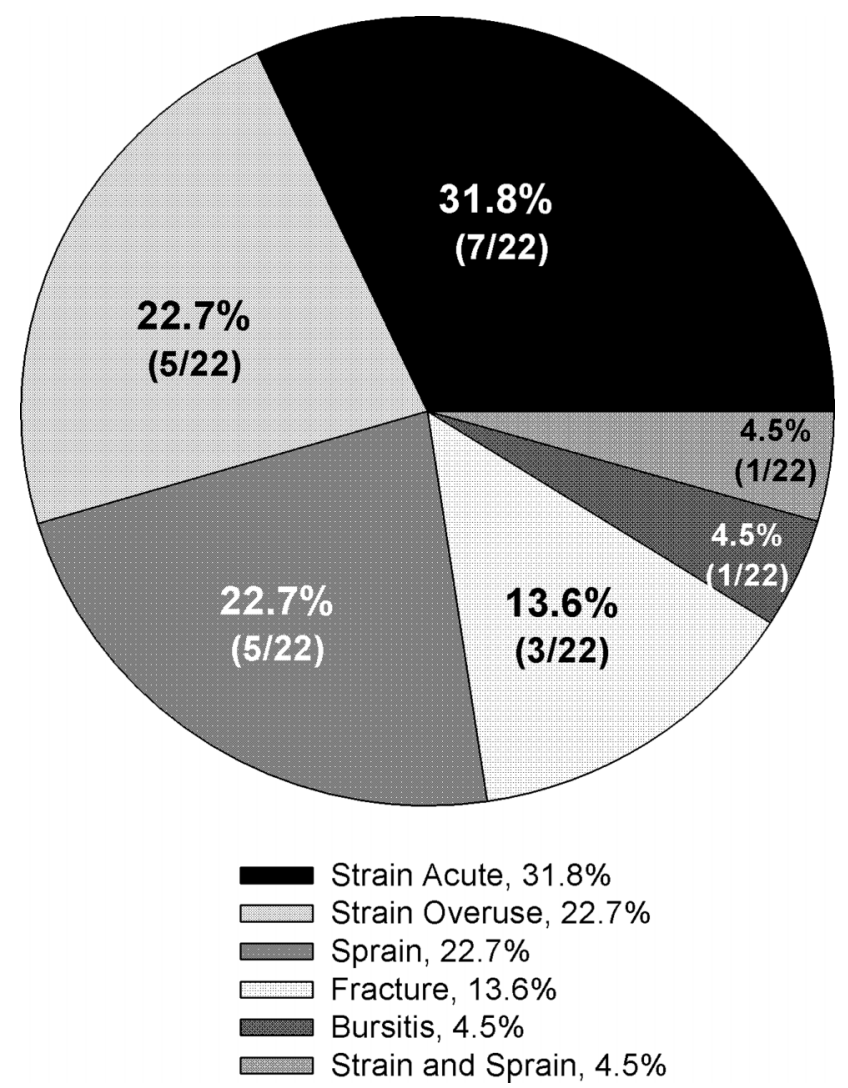

Figure 2 Type of injury. $\mathrm{n}=7$ ), while five injuries were acute muscle strains and eight were ligament sprains (figure 2). Overexertion/ strenuous movement was the most common cause of injury $(n=9)$, followed by six overuse/repeated strains and five falls (table 1).

Walking accounted for half of the activities during which injury occurred (table 1), with walking paths or sidewalks reported as being the most frequent locations of injury occurrence (table 1). Two of the 23 participants reported having more than one injury during the 12-month period. The more severe of the two injuries is included in the present description.

Seventy per cent of injuries (16/23) reportedly required medical treatment, with $75 \%$ being visits to a physician, $12 \%$ to a physical therapist, one to a walk-in clinic and one emergency room visit. The injury that resulted in an emergency room visit was by a 66-year-old female participant who incurred an injury to her trunk area while stretching and was unable to continue daily activities for 7 days postinjury. Those unable to continue exercising immediately totalled $44 \%$. Return-to-activity time varied from 1 to 182 days; excluding the most severe injury, the average return-to-activity time was 26 days. Seventeen of 23 individuals were limited in their normal activities and $13 / 23$ reported not being able to

\begin{tabular}{|c|c|c|}
\hline & N 23/167 & Per cent \\
\hline Cause of injury & $/ 23$ & \\
\hline Overexertion & 9 & 39.1 \\
\hline Overuse & 6 & 26.0 \\
\hline Fall & 3 & 13.0 \\
\hline Fall/overexertion & 2 & 8.7 \\
\hline Aggravated old injury & 1 & 4.5 \\
\hline Struck by object & 1 & 4.5 \\
\hline Unknown & 1 & 4.5 \\
\hline Exercise activity at time of injury & $/ 22$ & \\
\hline Walking & 11 & 50 \\
\hline Stretching & 2 & 9.1 \\
\hline Swimming & 2 & 4.5 \\
\hline Weight machines & 1 & 4.5 \\
\hline Hand held weights & 1 & 4.5 \\
\hline Tennis & 1 & 4.5 \\
\hline Volleyball & 1 & 4.5 \\
\hline Cycling & 1 & 4.5 \\
\hline Aquasize & 1 & 4.5 \\
\hline Jogging & 1 & 4.5 \\
\hline Location of injury & 122 & \\
\hline Walking path & 6 & 27.2 \\
\hline Sidewalk & 4 & 18.2 \\
\hline Home & 4 & 18.2 \\
\hline Pool & 3 & 13.6 \\
\hline Gymnasium & 2 & 9.1 \\
\hline Weight room & 2 & 9.1 \\
\hline Tennis court & 1 & 4.5 \\
\hline
\end{tabular}

For exercise activity at the time of injury and location of injury, information was available for only 22 participants due to missing data. 


\begin{tabular}{|c|c|c|c|c|c|c|}
\hline & Age & Sex & $\begin{array}{l}\text { Physical } \\
\text { activity level }\end{array}$ & $\begin{array}{l}\text { Frequency of exercise } \\
\text { participation }\end{array}$ & $\begin{array}{l}\text { Self-reported } \\
\text { injuries }\end{array}$ & \\
\hline \multirow[t]{2}{*}{ Age } & $\begin{array}{l}\text { Pearson } \\
\text { correlation }\end{array}$ & 1 & -0.234 & 0.021 & -0.008 & 0.099 \\
\hline & Significance & & 0.061 & 0.802 & 0.961 & 0.220 \\
\hline \multirow[t]{2}{*}{ Sex } & $\begin{array}{l}\text { Pearson } \\
\text { correlation }\end{array}$ & & 1 & -0.011 & 0.145 & -0.042 \\
\hline & Significance & & & 0.900 & 0.378 & 0.601 \\
\hline \multirow[t]{2}{*}{ Physical Activity Level } & $\begin{array}{l}\text { Pearson } \\
\text { correlation }\end{array}$ & & & 1 & -0.110 & -0.001 \\
\hline & Significance & & & & 0.530 & 0.990 \\
\hline $\begin{array}{l}\text { Frequency of Exercise } \\
\text { Participation }\end{array}$ & $\begin{array}{l}\text { Pearson } \\
\text { correlation }\end{array}$ & & & & 1 & -0.071 \\
\hline & Significance & & & & & 0.666 \\
\hline Self-Reported Injuries & $\begin{array}{l}\text { Pearson } \\
\text { correlation } \\
\text { Significance }\end{array}$ & & & & & 1 \\
\hline
\end{tabular}

continue participating for a period of time in their exercise routines.

Age, sex, total volume of physical activity and exercise frequency were neither correlated with (table 2), nor significant predictive variables of, injury occurrence when forced into a stepwise regression model.

\section{DISCUSSION}

This study provides novel descriptive data on the 12-month incidence of physical activity-related injuries in community-dwelling older adults over the age of 60 years. The participants had previously been enrolled in an exercise and education intervention where they were instructed on developing safe exercise routines utilising proper techniques. Postintervention, 29\% continued in various organised multicomponent group exercise programmes, while $71 \%$ were exercising independently in various exercise modalities. Of those exercising independently, walking was the most common activity, engaged in by $34 \%$ of the participants. Nineteen per cent of independent exercisers reported strength training as an activity.

This study found an exercise-related injury incidence rate of $14 \%$ in the older adult group (age range 6188 years). Larger epidemiological studies which examined injuries during participation in various general physical activities in populations spanning a large age range (but with limited numbers of older adults) reported injury rates of approximately 20\%. ${ }^{7}$ Similar studies for which the injury definition includes a criterion of an injury requiring medical attention reported injury rates of $11 \%,,^{5} 16.6 \%{ }^{17}$ and $5.6 \% .^{18}$ Often, large epidemiological studies do not report injury rates for age subgroups, or they lack sufficient sample sizes of older adults to report incidence rates for the oldest age groups. However, it would appear, based on our results, that older adults are not at increased risk for exercise-related injury. In fact, in comparison to a recent retrospective study of the exercise-related injury rates in older adults attending long-standing, supervised older adult fitness classes, ${ }^{4}$ the present study had a slightly lower injury rate $(14 \%$ vs $16 \%)$. While one might have expected that older adults attending supervised and specialised fitness classes would have lower rates of injury (vs the general exercising older adult population as in the present study), the incidence of injury is actually related to exposure in terms of time spent participating in activities for which there is an increased risk, including monitored exercise. It might also be suggested that participation in supervised exercise classes involves a greater motivation and encouragement for increased intensity. Studies comparing highly active older adults with their younger counterparts do not indicate that the injury rates are higher in the older age groups, ${ }^{7}$ 19-21 and perhaps most importantly, Carlson et $a l^{11}$ provided evidence that adults aged 65 and over, who are active at any level, have a lower incidence of non-sport or non-leisure-time injury than those who are inactive (OR 0.41 vs OR 0.61). As such, it appears that fears of increased susceptibility to injuries in the older adult population are unfounded, as per the literature available, and the benefits of exercise participation outweigh the risk of injury. ${ }^{22}$

Sex was not a significant predictor of exercise occurrence in the present study, and injury rates of $12.6 \%$ and $14.4 \%$ were documented for men and women, respectively. Similarly, larger epidemiological studies (however) across larger age ranges do not show increased injury rates between sexes. ${ }^{6}$

As walking is one preferred exercise modality among older adults, and as evidenced in the present study's population, it is not surprising that this was the leading activity at the time of injury (50\%). Similar results were 
observed in a 24-week walking intervention of women with a mean age of 60 years, which yielded an injury rate of $56 \%(\mathrm{n}=28) .{ }^{10}$ In contrast, Colbert $e t a l^{23}$ reported an injury rate of $18 \%$ in a large study of male and female regular walkers over the age of 45 years. This study proposed that greater amounts of walking do not increase the risk of injury and that the low risk of musculoskeletal injury in their study suggests that walking can be safely recommended as a way to improve fitness.

In the literature, the lower extremities are most often the location of reported injuries for all age groups and this trend is reflected in the present study as well. Overexertion and overuse were reported as the main causes of injury; Matheson $e t a t^{20}$ reported higher rates of overuse injuries in older versus younger athletes, most likely due to the musculoskeletal changes experienced with ageing.

One limitation of the present study is the relatively small sample size, which could have provided an incidence rate for injuries. While the participants for this study were identified at baseline and followed forward in time, the present study's description of injury occurrence was collected by retrospectively asking participants about their injuries every 6 months for 1 year. However, aside from the highly supervised exercise training studies, which are prospective, the majority of the literature describing injuries is epidemiological in nature and retrospective. Also, the present study utilised a tool which has been validated for older adults and shows high reliability of recall by older adults. As such, this limitation in potential recall bias is minimised. Lastly, the present sample represents an independent older adult population. Future studies should include a greater range of older adults and of predictor variables for injuries, including injuries incurred before the study period began.

The strengths of this study include a comprehensive description of exercise-related injuries focused on an older-adult age group. While many studies report injury incidence rates for specific activities, or for injuries presenting at hospital emergency rooms or medical clinics, the present study describes injuries of varying severity and relating to overall physical activity. In addition, this study represents a previously sedentary sample that received strategic guidance while beginning an exercise programme, and was prospectively followed to document injury incidence. As healthcare practitioners continue to encourage older adults to exercise in order to maintain health and independence with ageing, it is important to recognise that while it appears that injury rates do not increase with age, the injuries incurred do affect acute exercise participation and the implications of this, as well as of the preventative measures, need further study.

\section{CONCLUSIONS}

These results showed similar or lower exercise-related injury rates as compared with previous reports on younger and middle-aged adults. However, the definition of 'injury' and the criteria for reporting injuries vary in the literature. This study indicates that novice older adults initiating exercise are not at increased risk of injury. Nevertheless, in light of the fact that the injuries incurred limited daily activities and exercise participation (on average for 26 days), further research is needed in this area.

Author affiliations

${ }^{1}$ Canadian Centre for Activity and Aging, University of Western Ontario London, London, Ontario, Canada

${ }^{2}$ Faculty of Health Sciences, School of Kinesiology, University of Western Ontario, London, Ontario, Canada

Acknowledgements The authors would like to thank the Community Outreach Staff of the Canadian Centre for Activity and Aging for their assistance as well as the research assistants, Tara Clark, Debbie DeVries and Matthew McDonald.

Contributors RMDL, DAH and LS were responsible for the conception of the study. RMDL and LS were responsible for data collection and processing. All authors contributed to the analysis and interpretation of the data. RL and LS drafted the manuscript. All authors contributed towards revision of the manuscript and have approved the final manuscript.

Funding Funding for this study was supported by a Canadian Institute of Health Research Mobility in Aging Operating Grant (grant number 187595). The funding institution played no role in the conduct of this study.

Competing interests None.

Ethics approval University of Western Ontario Research Ethics Board.

Provenance and peer review Not commissioned; externally peer reviewed.

Data sharing statement No additional data are available.

\section{REFERENCES}

1. Crombie IK, Irvine L, Williams B, et al. Why older people do not participate in leisure time physical activity: a survey of activity levels, beliefs and deterrents. Age Ageing 2004;33:287-92.

2. Schutzer KA, Graves BS. Barriers and motivations to exercise in older adults. Prev Med 2004;39:1056-61.

3. The Canadian Fitness and Lifestyle Research Institute. Progress in prevention. Barriers to physical activity. 1996.

4. Stathokostas L, Theou O, Little RMD, et al. Physical activity related injuries in older adults-a scoping review. Sports Med 2013 (in press).

5. Mummery WK, Spence JC, Vincenten JA, et al. A descriptive epidemiology of sport and recreation injuries in a population-based sample: results from the Alberta Sport and Recreation Injury Survey (ASRIS). Can J Pub Health 1998;89:53-6.

6. Hootman JM, Macera CA, Ainsworth BE, et al. Epidemiology of musculoskeletal injuries among sedentary and physically active adults. Med Sci Sport Exer 2002;34:838-44.

7. Hootman JM, Macera CA, Ainsworth BE, et al. Predictors of lower extremity injury among recreationally active adults. Clin J Sport Med 2002;12:99-106.

8. Parkkari J, Kannus $\mathrm{P}$, Natri A, et al. Active living and injury risk. Int $J$ Sport Med 2004;25:209-16.

9. Kallinen M, Markku A. Aging, physical activity and sports injuries. An overview of common sports injuries in the elderly. Sport Medicine 1995;20:41-52.

10. Ready AE, Bergeron G, Boreskie SL, et al. Incidence and determinants o fin juries sustained by older women during a walking program. JAPA 1999;7:91-104.

11. Carlson SA, Hootman JM, Powell JH, et al. Self-reported injury and physical activity levels: United States 2000 to 2002. Ann Epidemiol 2006;16:712-19.

12. Mazzeo RS, Cavanagh $P$, Evans WJ, et al. Exercise and physical activity for older adults. Sport Med 1999;31:809-18.

13. Chen AL, Mears SC, Hawkins RJ. Orthopaedic care of the aging athlete. J Am Acad Orthop Surg 2005;13:407-16. 
14. Broderick CR, Winter GJ, Allan RM. Sport for special groups. Med J 2006;184:297-302.

15. ICECI Coordination and Maintenance Group. International Classification of External Causes of Injuries (ICECl). Consumer Safety Institute, Amsterdam and AlHW National Injury Surveillance Unit, Adelaide. version 1.22004

16. Gill DP, Jones GR, Zou GY, et al. The Phone-FITT: a brief physical activity interview for older adults. JAPA 2008;16:292-315.

17. Mummery WK, Schofield G, Spence JC. The epidemiology of medically attended sport and recreational injuries in Queensland. J Sci Med Sport 2002;5:307-20.

18. Schneider S, Seither B, Tonges S, et al. Sports injuries: population based representative data on incidence, diagnosis, sequelae, and high risk groups. Br J Sport Med 2006;40:334-9.
19. Kannus $\mathrm{P}$, Niittymaki S, Jarvinen $\mathrm{M}$, et al. Sports injuries in elderly athletes: a three-year prospective, controlled study. Age Ageing 1989;18:263-70.

20. Matheson GO, Macintyre JG, Taunton JE, et al. Musculoskeletal injuries associated with physical activity in older adults. Med Sci Sport Exer 1989;21:379-85.

21. Kujala UM, Nylund T, Taimela S. Acute injuries in orienteerers. Int $J$ Sport Med 1995;16:122-5.

22. Farahmand B, Broman G, Defaire U, et al. Golf: a game of life and death- reduced mortality in Swedish golf players. Scand J Med Sci Sport 2009;19:419-24.

23. Colbert LH, Hootman JM, Macera CA. Physical activity-related injuries in walkers and runners in the Aerobics Center Longitudinal Study. Clin J Sport Med 2000;10:259-63. 